Provided by the author(s) and University of Galway in accordance with publisher policies. Please cite the published version when available.

\begin{tabular}{|c|c|}
\hline Title & $\begin{array}{l}\text { Exploring Community Perceptions of the relationship between } \\
\text { age and social exclusion in rural areas }\end{array}$ \\
\hline Author(s) & Walsh, Kieran; O'Shea, Eamon; Scharf, Thomas \\
\hline $\begin{array}{l}\text { Publication } \\
\text { Date }\end{array}$ & $2012-02$ \\
\hline $\begin{array}{l}\text { Publication } \\
\text { Information }\end{array}$ & $\begin{array}{l}\text { Walsh, K., O'Shea, E., Scharf, T. (2013) 'Exploring } \\
\text { Community Perceptions of the relationship between age and } \\
\text { social exclusion in rural areas'. Quality In Ageing, } 13 \text { (NO. } \\
\text { 1):16-26. }\end{array}$ \\
\hline Publisher & Emerald \\
\hline $\begin{array}{l}\text { Link to } \\
\text { publisher's } \\
\text { version }\end{array}$ & http://dx.doi.org/10.1108/14717791211213580 \\
\hline Item record & http://hdl.handle.net/10379/3212 \\
\hline DOI & http://dx.doi.org/DOI 10.1108/14717791211213580 \\
\hline
\end{tabular}

Downloaded 2023-04-26T01:22:42Z

Some rights reserved. For more information, please see the item record link above. 


\title{
Exploring community perceptions of the relationship between age and social exclusion in rural areas
}

\author{
Eamon O'Shea, Kieran Walsh and Tom Scharf
}

\author{
Eamon O'Shea is a \\ Professor, Kieran Walsh is a \\ Research Fellow and \\ Professor Tom Scharf is \\ Director, all at the Irish \\ Centre for Social \\ Gerontology, National \\ University of Ireland \\ Galway, Galway, Ireland.
}

The authors would like to thank the Centre for Ageing Research and Development in Ireland

(CARDI) for funding this project and the various rural communities for participating in the research.

This work was conducted in collaboration with members of the Healthy Ageing in Rural Communities (HARC) cross-border research network (www.harcresearch.com).

\begin{abstract}
Purpose - This paper aims to explore, for the first time, community perceptions of the relationship between age and social exclusion in rural areas of the Republic of Ireland and Northern Ireland.

Design/methodology/approach - The paper builds on learning from a previous baseline cross-border rural ageing study and draws its methodology from a broader ecological multi-level approach. The research was conducted through focus groups with community stakeholders, which were undertaken in ten communities in different rural settings (village, near-urban, island, dispersed, and remote) in both the Republic of Ireland and Northern Ireland.
\end{abstract}

Findings - In total, four interconnecting thematic areas emerged as important in determining exclusion or inclusion for older people living in rural areas: place, economic circumstances, social provision, and social connectedness. Within these themes, various tipping points emerged as important for pathways into and out of exclusion, most notably local systems of social support and the mindset of older people themselves in relation to participation.

Originality/value - This research lays the foundations for understanding the lived experiences of older people on the island of Ireland and the pathways for their inclusion and exclusion in diverse rural areas, as seen through the lens of community stakeholders.

Keywords Ireland, Ageing, Rural, Social exclusion, Stakeholders

Paper type Research paper

\section{Introduction}

Social exclusion amongst rural-dwelling older people is not well understood, particularly on the island of Ireland. We still have insufficient knowledge of what it is like to grow old in a rural community (Burholt, 2006; Heenan, 2010) and of the associated opportunities and challenges for ageing individuals. Added to this is a lack of conceptual understanding and empirical data surrounding exclusion in rural places (Commins, 2004) and the role that age plays in mediating or exacerbating exclusionary processes (Scharf et al., 2005). In the Republic of Ireland and Northern Ireland, there has been both a political and social discourse on elements of rural ageing, but such discourse has typically been superficial and lacking a meaningful research base and policy focus. As a result, rural older people are sometimes viewed as a homogenous group living in homogenous and stagnant communities (NESF, 2005; O'Shea, 2007). In effect, the diverse roles, vulnerabilities and lifecourse trajectories of older people in rural communities have been overlooked (Le Mesurier, 2003; O'Shea and Conboy, 2005). The reality of rural ageing is a more complex dynamic; one where older people are both active and passive, engaged and disengaged, present and absent.

Addressing this complexity represents a key challenge for researchers. For example, we know little of how rural communities respond to ageing demographics and shifting economic and social structures. Nor do we know if differing geographical and social contexts impact on the capacity of local areas to maintain a sense of community and inclusion for older 
people. Most importantly, we do not know how exclusion is understood or addressed in these communities. Certainly, there has been some evidence to indicate that growing older in rural places can be accompanied by a high risk of poverty, deprivation, isolation and loneliness (Wenger, 2001; NCAOP, 2001; Rural Community Network, 2004; Savikko et al., 2005). While there are sometimes difficulties in identifying the prevalence and mechanisms of poverty and exclusion in rural communities, the reality of rural life can be unsympathetic (Shucksmith and Chapman, 1998; Commins, 2004; Scharf and Bartlam, 2008). At an emotional and an idealised level, rural ageing can sometimes inspire a rhetoric of close-knit, supportive communities for older people nestled in scenic landscapes. However, this perspective has increasingly been subject to critical review (Rowles, 1988; Magilvy and Congdon, 1994; Wenger, 2001; Keating et al., 2005; Walsh and O'Shea, 2008).

This article explores some of the concerns around existing views of rural ageing. Representing the first stage of a detailed examination of social exclusion and ageing in diverse rural communities on the island of Ireland, it reports on the views of local stakeholders in diverse rural places regarding the potential for inclusion and exclusion in later life in their localities.

\section{Background}

\section{Social exclusion, ageing and place}

Social exclusion represents a complex and multi-dimensional phenomenon. It involves the lack or denial of resources, rights, goods and services, and the inability to participate in the normal relationships and activities, available across economic, social, cultural or political arenas to the majority of people in a society (Levitas et al., 2007).

Exclusion affects both the quality of individuals' lives and the equity and cohesion of society as a whole, including the role of institutional structures in facilitating or fettering rights and responsibilities (Saunders et al., 2008). In attempting to model exclusion, Commins (2004) focuses on five potential domains; economic production and exchange; welfare state provision; political governance; cultural values and norms and affective familial and social networks and relationships. Room (1999) also highlights the importance of relational connectivity and empowerment, combined with the existence of collective local resources and infrastructure, to overcome multidimensional disadvantage. Similarly, the Bristol Social Exclusion Matrix identifies resources, participation and quality of life as central to inclusion (Levitas et al., 2007). The issue of how to model social exclusion remains problematic, however, complicated by the interdependence of social phenomena and individual responses to both events and transitions across the life course.

The nature and perception of place in rural areas can further complicate social exclusion classification. The accumulation of memories, attachments and associations that arise from living and ageing in place may reinforce the personal identity of rural dwellers (Rowles, 1983, 1993; Heenan, 2010). It is this role of place as a setting of experience and relationships that leads to an emotional bond or attachment between people and places (Shumaker and Taylor, 1983; Rubinstein and Parmelee, 1992; Gustafson, 2001). The notion of place attachment features strongly in rural ageing studies and has been suggested by Burholt (2006) to comprise: location satisfaction; historical perspective; aesthetic and emotional components of location; social support; social integration; appropriateness of the environment; and relocation constraints. The question then is whether or not place attachment itself serves as a compensating factor for what some have considered the combined effects of age-related vulnerabilities and rural deprivation (Krout, 1986; Joseph and Cloutier-Fisher, 2005). Rural places are, thus, diverse and complex constructions in themselves and are more than just simple locations for people and their experiences.

Older people's experiences of ageing in rural areas are inextricably linked to social policy, a potentially hazardous relationship given the negative connotations with which ageing has traditionally been associated in European and North American social policy contexts (Pierce, 2008). As Estes (1979) notes, what is done for and about older people, including knowledge gained from research, reflects our conceptions of ageing, which in many 
instances are negative and discriminatory. Therefore, a key challenge facing policymakers is to value and understand the world of older people as subjects (Pierce, 2008). The centrality of context, particularly in relation to communities and places, is crucial in understanding the experience of social exclusion among older people. Recognition of the different ways social exclusion can impact on older people in rural areas calls for a community-based approach that draws on the knowledge, perceptions and misperceptions of older people and the communities within which they live. As Chamberlayne et al. (2002) suggest, allowing frameworks of social exclusion to be informed by people's subjective experience is one way to avoid the imposition of policies that treat those deemed "socially excluded" as a homogenous group.

Against this background, this article seeks to lay the foundations for understanding the lived experiences of older people on the island of Ireland by first exploring the key community understandings and pathways of inclusion and exclusion in a diverse group of rural places. In particular, we are interested in the role of place, economic, infrastructural and social factors in shaping these pathways, given the importance of these issues in the literature.

\section{Methodology}

This paper focuses on the role of the community and its understanding of the relationship between ageing and social exclusion in rural areas of Ireland. It builds on learning from a previous baseline rural ageing study (Walsh et al., 2010) and draws its methodology from a broader ecological multi-level approach (Thrift, 1999; Conradson, 2005). To account for the diversity of rural places, the research concentrated on five different rural community types: dispersed rural, remote rural, island rural, village rural and near-urban rural on both sides of the border on the island of Ireland (Figure 1). This descriptive classification was derived from

\section{Figure 1 Map of participating sites}

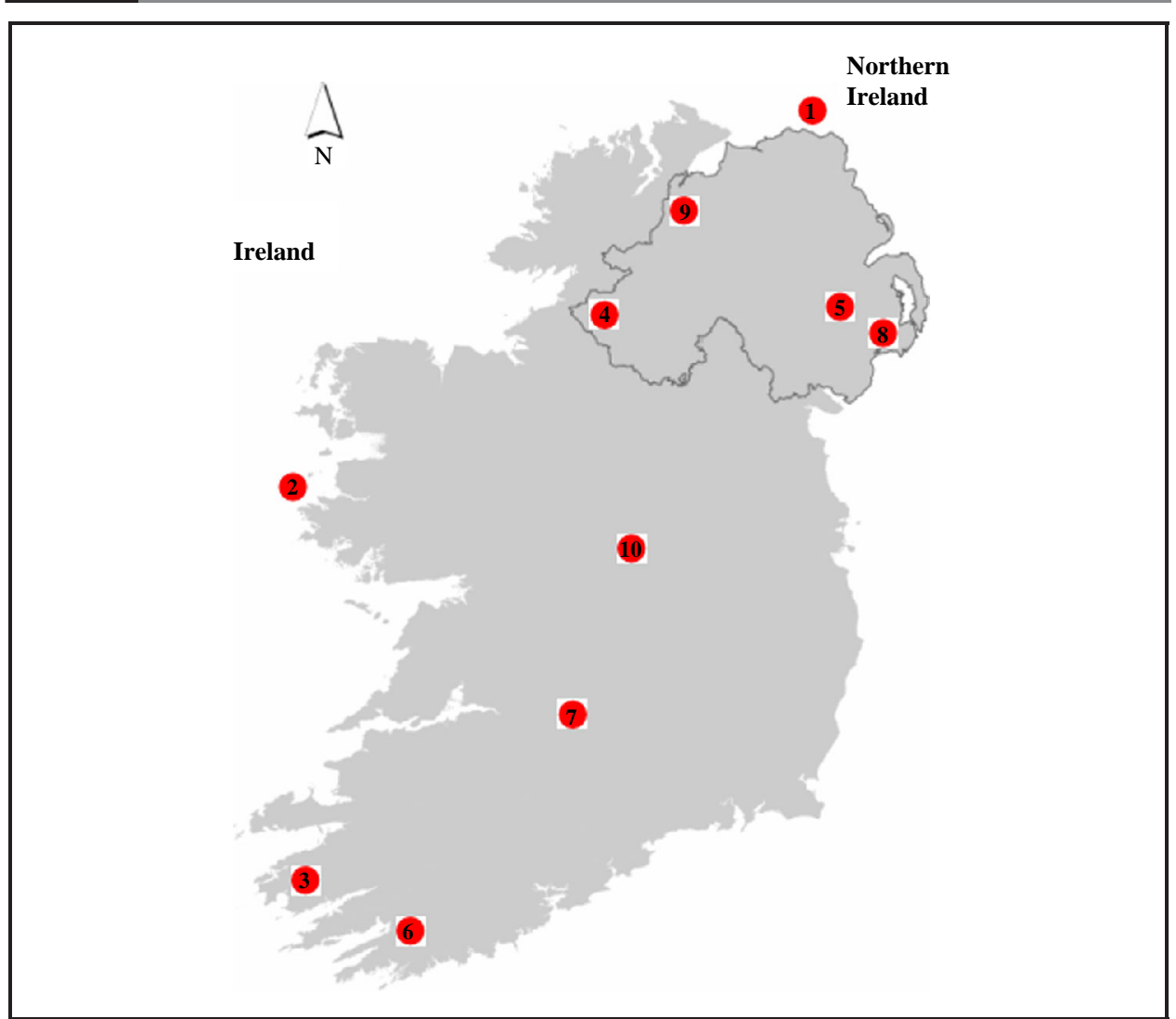


the Department for Environment, Food and Rural Affairs rural classifications in the UK and the Irish Rural Structure and Gaeltacht Areas Report rural typology in Ireland. The communities and a brief description of each site are presented in Table I.

Focus group discussions were held in each rural community with stakeholders drawn from the public, private and voluntary sectors. The discussions sought to gain understanding of the potential for inclusion and exclusion of older people within each case-study site, with a particular emphasis on how the physical, economic and social characteristics of these places facilitated or hindered older people's social inclusion. Participants were selected on the basis of their professional, voluntary and developmental role in each of the case-study sites. Participants included voluntary service providers, home-care workers, community workers, public health representatives, retired professionals (for example, post office master and nurse), and local representatives from national bodies and charities (for example, Society of St Vincent de Paul, Irish Farmers' Association and the Gaelic Athletic Association (GAA)). Community consultations typically lasted 90 minutes, and involved 62 participants across the ten sites.

There are a number of caveats associated with selecting the case-study communities. First, no exercise of this kind can hope to capture the full heterogeneity of rural communities on the island of Ireland. Second, a focus group methodology, however carefully constructed, can never be fully representative of all rural community stakeholders. Third, Northern Ireland is a more urban society than the Republic of Ireland. This is evident in the population densities in the two regions (Ireland: 60 persons per square kilometre - CSO, 2006; Northern Ireland: 132.5 persons per square kilometre - NISRA, 2009) and the proliferation of large regional towns in Northern Ireland. Fourth, there can be significant variation in geographic, infrastructural and community characteristics even within places, where relatively small distances might be associated with considerable differences in the lived experiences of older

\section{Table I Case-study sites}

Name (site number)

Description

Population structure

\begin{tabular}{|c|c|c|}
\hline \multicolumn{3}{|c|}{ Island rural } \\
\hline 1. Rathlin & Island off the north coast of County Antrim with & \\
\hline Northern Ireland & Scots-Irish heritage with 100 inhabitants approx. & $32.6 \%$ (60 and over) \\
\hline $\begin{array}{l}\text { 2. Inishbofin } \\
\text { Ireland }\end{array}$ & $\begin{array}{l}\text { Non-Gaeltacht island off the north-west coast of } \\
\text { County Galway with } 200 \text { inhabitants approx. } \\
\text { Remote rural }\end{array}$ & $16.5 \%$ (65 and over) \\
\hline $\begin{array}{l}\text { 3. Dromid } \\
\text { Ireland }\end{array}$ & $\begin{array}{l}\text { Village in Gaeltacht area in south County Kerry, } \\
\text { considered the newest village in Ireland }\end{array}$ & $13.3 \%$ (65 and over) \\
\hline 4. Garrison & Village in border area of West-Fermanagh, which & \\
\hline Northern Ireland & $\begin{array}{c}\text { had cross-border roads barricaded until } 1995 \\
\text { Dispersed rural }\end{array}$ & $23.9 \%$ (60 and over) \\
\hline $\begin{array}{l}\text { 5. Finnis } \\
\text { Northern Ireland }\end{array}$ & $\begin{array}{l}\text { Hamlet and dispersed settlements situated on a } \\
\text { townland and local authority junction in County }\end{array}$ & \\
\hline & Down & $21.3 \%$ (60 and over) \\
\hline $\begin{array}{l}\text { 6. Coomhola } \\
\text { Ireland }\end{array}$ & $\begin{array}{l}\text { Valley in south-west County Cork encompassing } \\
\text { a series of townlands with dispersed dwelling }\end{array}$ & \\
\hline & $\begin{array}{l}\text { patterns } \\
\text { Village rural }\end{array}$ & $14.7 \%$ (65 and over) \\
\hline $\begin{array}{l}\text { 7. Upperchurch } \\
\text { Ireland }\end{array}$ & $\begin{array}{l}\text { Village situated in the hills of mid-Tipperary in the } \\
\text { Irish mid-west region }\end{array}$ & $19.1 \%$ (65 and over) \\
\hline 8. Clough & Accessible village situated within principle & \\
\hline Northern Ireland & $\begin{array}{c}\text { commuting zone for east County Down } \\
\text { Near-urban rural }\end{array}$ & $14.2 \%$ (60 and over) \\
\hline $\begin{array}{l}\text { 9. Donemana } \\
\text { Northern Ireland }\end{array}$ & $\begin{array}{l}\text { Accessible village situated in close-proximity to } \\
\text { major regional urban centre in north County }\end{array}$ & \\
\hline & Tyrone & $19.8 \%$ (60 and over) \\
\hline $\begin{array}{l}\text { 10. Rosemount } \\
\text { Ireland }\end{array}$ & $\begin{array}{l}\text { Accessible village situated in close-proximity to } \\
\text { three major urban centres in south-west }\end{array}$ & \\
\hline & Westmeath & $11.2 \%$ (65 and over) \\
\hline
\end{tabular}


people. Although, these issues have implications for comparing experiences across places, it must be recognised that they reflect the real-life complexity and diversity of rural communities.

\section{Results}

Four interconnecting thematic areas emerge as important in determining exclusion or inclusion for older people living in rural areas. These are place, economic circumstances, social provision, and social connectedness.

\section{Place}

Participants in Garrison and Dromid (both remote) and in Coomhola (dispersed) emphasised the rurality that characterised their communities and the wider geographic region. Here, rurality was associated with long distances, population sparseness, small-scale agricultural production and, in some cases, a sense of remoteness and isolation. According to stakeholders, distance and isolation did not automatically imply exclusion but they certainly rendered inclusion more problematic. This was true too for the island communities (Rathlin and Inishbofin). In these cases though, seasonal factors appeared to influence their rural nature. While winter months and harsh weather conditions accentuated the sense of rurality, summer tourism appeared to mask the islands' more isolating elements. Stakeholders in these communities recognised the relative nature of the exclusionary process in the context of geographic elements of place:

Firstly, anyone who lives on an island is socially excluded immediately [...] (Stakeholder, Inishbofin).

Stakeholders from Upperchurch and Clough (both villages), Rosemount and Donemana (both near-urban), and to a lesser degree Finnis (dispersed), highlighted the centrality of their communities with respect to large regional towns and cities. A clear sense of accessibility removed any notion of geographic remoteness from their experience of rurality. While participants in most of these communities still considered themselves to be very much rooted in rural areas, stakeholders in Clough noted how the centrality of the community served to subdue the rural features of the place. In all of the sites, participants highlighted the subjective nature of both place and exclusion. In particular, a recurring theme was that distance from others did not always lead to exclusion or poor quality of life:

My father now is 90 and he's living on his own about two miles from any house anywhere. He wouldn't get out of there [...] I mean, he's happy as Larry [phrase to indicate being happy as possible] [...] I mean for him it's good how isolated it is [...] (Stakeholder, Dromid).

\section{Economic circumstances}

In each of the case-study sites, stakeholders described how a combination of macro-level factors, including mechanisation, declining farm production, rural decline, centralisation, service re-structuring and rural development strategies, have transformed local economies, impacting directly on economic opportunities for rural residents and rural settlement itself. The concern among some stakeholders was that these changes have sometimes undermined the cohesive capacity of communities and their ability to maintain an inclusive active and engaged environment for older people.

Much of the discussion with community stakeholders on economic factors focused on the past and present role of the agricultural sector within their community and the economic implications of the changes arising from the sector's diminished importance. Increasingly, the agricultural and fisheries sector served as a smaller component of the local economy and provided less economic opportunities for community residents leading to structural adjustment at best and exclusion at worst:

Well, agriculture, yes, but [... ] today it would be a one-man operation now. Years ago it used to be five or six men. So now it's down to just one man (Stakeholder participant, Finnis).

While participants across several sites stated that farming was still relatively strong, the majority of farmers in these communities now work on a part-time basis and rely on public 
subsidy payments and disparate sources of off-farm employment for their income. In several sites, the construction sector has been a major employer and supplier of trades-related work. Now that work in this sector has diminished, as a result of the current recession, people worried about the social and economic consequences, as younger people are forced to move away from home to find work. People were concerned not only about effects on family networks and relationships, but also about the impact of population decline on local economic activity and service provision. As one participant describes, commuting was one of the few ways in which members of the younger generation could hope to remain in the area:

I feel that the best we can hope for, not ideal as I've said already, but the best we can hope for is that [...] people will build here and commute (Stakeholder, Upperchurch).

Emigration was perceived to be a growing problem in many areas. While in recent years, migration from these communities involved younger people moving to urban centres for third-level education and/or employment, international emigration was increasingly prevalent because of the economic recession:

There's still a fair wee bit of emigration from here [.. . ] thirty young men went to Australia inside two months. That's hard to believe [...] (Stakeholder, Finnis).

Participants expected that economic conditions would worsen in the future. That said, there was an acknowledgement that communities had suffered similar severe periods of economic decline in the past and, with support, could endure the current period of economic difficulty. Participants referred to the hard-working nature of rural people, their capabilities and their adaptive capacity:

One thing I notice about Coomhola is that there are a lot of fellas started off their own little businesses and, thanks be to God, the recession hasn't closed any of them down yet. But I think that's a very important thing (Stakeholder, Coomhola).

\section{Social provision}

Within each case-study site, participants described a health and social service infrastructure that was reliant on both public and community-based voluntary components. It was also evident that the public services available to people in rural areas varied widely across the ten sites. Generally, participants in the more remote and scattered areas described a health and social services infrastructure that was typically weak. Those in the more populated regions tended to describe a more accessible state infrastructure, either in the immediate community or within close proximity.

Such distinctions reflect traditional critical mass and economy of scale imperatives in respect of social services provision. Our data suggest that public service provision and related infrastructure is generally stronger in communities in Northern Ireland than in the Republic of Ireland. While the higher population density in the north is certainly likely to be a factor in explaining that difference, so too is the more developed welfare state in that region and a greater emphasis on universal provision.

Public health and district nurses were especially praised in geographically isolated and dispersed settlements as being important in keeping dependent older people connected to their local surroundings, acting as both provider and mediator of state organised health and social care:

It's the security (of the district nurse) especially for someone older, or for anyone [ . . . ] if something did happen after 5 o' clock in the afternoon that you can have somebody there [... . (Stakeholder, Rathlin Island).

Participants across all sites also noted the importance of home helps, particularly in relation to combating loneliness:

(A) big benefit we find say from the home help service [ . . ] It's having someone to talk to or having someone to talk with, whether it's about the weather, how they're feeling or just general chitchat. It's invaluable (Stakeholder, Coomhola). 
Stakeholders reported that any reduction in public services places an increasing burden of responsibility on families and community groups. Accordingly, in all case-study sites, participants described how the community and voluntary sector dominates the community fabric and drives much of the social provision for older people:

If one was dependent on the state services or semi-state services or public services to look after every single person in the community, there would be a lot of problems in the community [...] the voluntary groups are coming in and doing a huge amount of work that I suppose [...] should be done by a state agency (Stakeholder, Upperchurch).

It is unsurprising then that stakeholders in the majority of communities were more concerned with retaining the existing state infrastructure than attempting to negotiate new state provision. Overall, there was a strong sense of frustration evident when discussing the weakness of public service provision. While participants recognised current economic constraints, they felt marginalised as communities.

\section{Social connectedness}

Participants highlighted the changes that have weakened the social fabric of rural places, thus contributing to potential social exclusion. Primarily, participants noted the loss of natural meeting-points for rural people. Post-offices, pubs, police stations, creameries and local shops had closed in many communities over the years. While the loss of these facilities reflected a major decline in physical infrastructure, their loss as community interfaces was thought to especially impact on the social lives of older residents:

And that was another sad thing that happened in rural Ireland, because the post office is a great place. Well certainly for senior citizens to meet and chat. And that was a sad thing (Stakeholder, Rosemount).

Participants in a number of sites highlighted how understandable restrictions on alcohol intake and driving meant that some older men were now afraid to drive to the local pub, with consequent negative implications for the maintenance of existing social networks. The declining role of religion and religious institutions was also mentioned as impacting negatively on social interaction. The local church was no longer attended by all members of the community and, therefore, was no longer a broad community-based interface.

Yet, even in the face of fundamental changes to social and economic structures, some participants still considered their communities as conforming to the rural idyll of being close-knit, supportive, places that recognised and celebrated the value of older people. Stakeholders generally asserted that neighbourliness and a willingness to help older people were still prominent features of the community landscape. In some cases this was reinforced by the work of local organisations (for example, community associations, not-for-profit groups, church groups, sporting organisations).

You'll find in a city [.. . ] you tend to lock your door, you go inside and sit and nobody knows your neighbour either side of you. You never know who's there, you know. But I certainly think around here they do tend to look out for each other and care more about (each other) (Stakeholder, Clough).

Participants suggested that communities tended to offer most help in times of immediate crises. This was particularly true when somebody from the locality died. Indeed some participants referenced well-attended funerals and the assistance given to families after bereavement as an indicator of the strength of the community:

If there's a problem, people will come and give help, no problem [ . . . ] if somebody dies, you might say that all the neighbours gather around them and they're looked after. The relatives and all. It's just one of those things. They'd attend wakes (Stakeholder, Donemana).

For some people, this unity of purpose was a reflection of the communal nature of rural places and the traditional reciprocity and interdependency that underlined rural social structures. Health and social care professionals sometimes involved the local community in helping to identify vulnerable members of society and with their recruitment into support groups or communal self-help activities. Inherent within this form of interdependency is a flexibility that serves to broaden the remit and responsibilities of individuals, groups and services. 
This is illustrated by the voluntary coordinator of rural transport in one locality, who referred to the activities of the rural transport driver:

He [rural transport driver] said today I put a handle on a shovel; I put a slate on a roof; I put a bulb in a house; and I brought a coffee cake to a woman. And they were all people that weren't on the bus (Stakeholder, Rural community).

Although such interdependency was rarely formalised, participants, especially in the island communities, felt that this kind of cooperation was a fundamental element of rural life. It also reflected the fact that many of the service providers (state, voluntary or private) were also residents of the local community.

Finally, accessibility was seen as influencing connectedness. In the absence of comprehensive public transport, car ownership was considered essential to allow older people to participate fully in their communities, particularly for people who lived "off the beaten track" or who had physical disabilities:

I mean, if they're not mobile and they can't drive a car, I mean, they have to be taken everywhere.

Well, I mean, they're depending on somebody to come to them (Stakeholder participant, Dromid).

\section{Tipping the balance}

The data from the focus groups highlight the importance of economic issues, social provision, social connectedness and place in influencing the potential for inclusion and exclusion in rural areas, confirming trends in the literature identified earlier. Of course, making sense of these findings requires some understanding of the baseline reference point for respondents in relation to inclusion and exclusion. Mostly, and in the case of participants in this study, judgements in relation to social exclusion can only be made on a subjective basis, linked to experience and perception, even if the latter is based on incomplete knowledge and information. With that caveat in mind, stakeholders generally felt that the potential for inclusion among rural older people in relation to these four elements was greater than the potential for exclusion. However, it was mainly through community-based work and voluntary-organised activity at the local level that the balance was tipped in favour of inclusion. The state was mostly seen as the residual partner in combating exclusion.

Participants referred to the work done by local organisations and individuals to enhance the connectedness and well-being of older people in the case-study sites. Examples included day centres, meals-on-wheels services, luncheon clubs, social and community centres, cards, sport, church, bingo, retirement groups, women's groups, men's groups, adult education, art classes and befriending services. In many cases, these voluntary activities were the primary social and service activity for older people in these communities. Not surprisingly, therefore, participants worried about the ability of communities to continue to respond to gaps in public provision since the latter were likely to widen in the future. Participants were also aware that community and voluntary effort could only achieve so much and that many forms of exclusion were not amenable to change without significant public intervention.

Community stakeholders also identified particular attributes and circumstances, including major life events, which increased the potential for older people to become excluded in rural areas. Living outside core settlements in the countryside without access to private transport was identified as a major risk factor for exclusion. Moreover, having to stop driving, or no longer being able to rely on someone else to drive, for example through bereavement, was seen as giving rise to a difficult period of transition and thereby increasing the potential for exclusion.

Older people with limited financial resources also emerged as a concern for some community stakeholders. In the Republic of Ireland, that concern was largely focused on older women with little attachment to the labour force over their lifetime. In Northern Ireland, participants highlighted the low value of the state pension, although the potential to qualify for other state benefits was acknowledged (for example, disability and single pensioner allowances) as an important counter-balance to less generous pension payments. The cost of fuel was also referenced as creating difficulties for some older people. It was acknowledged 
by many participants that some older people did not always spend money even when they had it, mainly through fear that they would not have enough for the rainy day later on, particularly should they become sick and need nursing home care.

Stakeholders highlighted that older people living alone (through bereavement or otherwise) and/or suffering from a disability or ill-health were another group who were at risk of becoming socially excluded. While the public health nurse and home help modified such risks, there was still a concern that the most vulnerable older people were either unknown to the community or were outside the community's structures and influence, however caring that community might be. Stakeholders in a number of case-study sites also suggested that new residents were less likely to be included in a rural community. It was felt that older retirement migrants, with no previous connection to the area, had fewer opportunities or network relationships available to them to integrate fully into the locality.

The most commonly cited risk factor for exclusion, however, was said to be the mind-set of older people themselves. Within each community, stakeholders recognised that it was difficult to get some older people to participate in community activities or to avail of a specific service. Stakeholders offered several potential reasons for older people not engaging. Sometimes older people did not want to accept what might be perceived as charitable assistance because of a negative stigma. Some older people believed that they were now well-off in comparison to what they, or previous generations, had in the past and consequently any public assistance was unnecessary and undeserved. For others, isolation was seen as a personal choice, enforced in the case of some older men by gendered social roles, which compounded the difficulty of engaging them in activities that they had not participated in previously.

According to participants in this study, these factors combined to varying degrees to create stoicism among some older people, which led to them being excluded from normal activities of daily living. A mixture of resilience, pride and ignorance combined to keep some older people marginalised and outside of public and social spheres of influence. The problem identified by stakeholders is that in the absence of multi-level agencies of social support incorporating state, community and informal structures, such withdrawal can have serious health consequences for some of these people, leading to undiagnosed illness, up to and including premature death. While failure of any one of the key systems of social support may result in exclusion of an individual, the view of focus group participants was that failure of multiple systems will almost certainly produce exclusion.

\section{Conclusions}

Recognising inclusion and exclusion among older people is a difficult task, especially at the community level. Yet, this paper contributes some important insights to the international literature. The findings from the focus groups, including consideration of the key tipping points, illustrate the complexity of rural communities in terms of: their rapidly changing economic and social structure; their relationship with the state; their capacity for innovation; and their ability to adapt. Additionally, the paper points to the impact of place, economic, infrastructural and social factors on the capacity of rural communities to combat the exclusion of older people. Its findings also contribute to the emerging field of rural gerontology in the cross-border context of the Republic of Ireland and Northern Ireland.

Even though participants in all sites considered that there was a greater potential for inclusion than exclusion in their "close-knit" communities, it is impossible to tell from the site visits if this was true, or whether any single community contained the potential for greater or lesser exclusion than any other. Communities are likely to conceptualise vulnerability in older populations differently, just as older people do themselves. What is evident from the focus groups is how much voluntary and community-based work is being done in rural communities to compensate for the absence of a comprehensive public policy to address exclusion among older people.

More information is now required on the nature and depth of exclusion as experienced and narrated by older people. It is for that reason that we must consider the lived experiences of older people in rural communities, which is what we intend to do in subsequent 
publications arising from the study reported here. This will also assist in developing our conceptual understanding of the social exclusion of rural dwelling older people and the role of both rurality and age in that exclusionary process. For now, however, what we can say with certainty, based on the testimony of community stakeholders, is that place, economic circumstances, social connectedness and social provision matter for the inclusion of older people living in rural areas, independently and in combination.

\section{Implications for policy and practice}

- There needs to be a reassessment of the relative weighting given to efficiency and equity in public policy-making for rural areas.

- Place, economic circumstances, social provision, and social connectedness are important factors in determining social exclusion or inclusion in rural areas.

- There is a need to understand more fully the nature of inclusion and exclusion in rural communities, taking into account groups of older people which are more susceptible than others to poverty and multiple forms of deprivation.

- A comprehensive public policy to address exclusion among older people living in rural areas is required. The gaps are currently being filled by voluntary and community-based work.

\section{References}

Burholt, V. (2006), '“Adref': theoretical contexts of attachment to place for mature and older people in rural north Wales", Environment and Planning, Vol. 38, pp. 1095-114.

Chamberlayne, P., Rustin, M. and Wengraf, T. (Eds) (2002), Biography and Social Exclusion in Europe: Experiences and Life Journeys, The Policy Press, Bristol.

Commins, P. (2004), "Poverty and social exclusion in rural areas: characteristics, processes and research issues", Sociologia Ruralis, Vol. 44, pp. 60-75.

Conradson, D. (2005), "Landscape, care and the relational self: therapeutic encounters in rural England", Health and Place, Vol. 11, pp. 337-48.

CSO (2006), Census 2006, Central Statistics Office, Dublin.

Estes, C.L. (1979), The Aging Enterprise, Jossey-Bass, San Francisco, CA.

Gustafson, P. (2001), "Meaning of place: everyday experience and theoretical conceptualisations", Journal of Environmental Psychology, Vol. 21, pp. 5-16.

Heenan, D. (2010), Rural Ageing in Northern Ireland: Quality of Life Amongst Older People, Office of the First Minister and Deputy First Minister, Belfast.

Joseph, A.E. and Cloutier-Fisher, D. (2005), "Ageing in rural communities: vulnerable people in vulnerable places", in Andrews, G.J. and Philips, D.R. (Eds), Ageing and Place: Perspectives, Policy, Practice, Routledge Studies in Human Geography, Taylor \& Francis Group, London.

Keating, N., Swindle, J. and Foster, D. (2005), "The role of social capital in ageing well", Social Capital in Action: Thematic Policy Studies, PRI Project, Policy Research Initiative, Ottawa.

Krout, J.A. (1986), The Aged in Rural America, Greenwood Press, Westport, CT.

Le Mesurier, N. (2003), The Hidden Store: Older People's Contribution to Rural Communities, Age Concern England, London.

Levitas, R.A., Pantazis, C., Fahmy, E., Gordon, D., Lloyd, E.H.R.R. and Patsios, D. (2007), The Multi-dimensional Analysis of Social Exclusion, Department for Communities and Local Government (DCLG), Cabinet Office, Social Exclusion Task Force, London, available at: www. cabinetoffice.gov.uk/social_exclusion_task_force/publications/multidimensional.aspx

Magilvy, J.K. and Congdon, J.G. (1994), "The crisis nature of health care transitions for rural older adults", Public Health Nursing, Vol. 17 No. 5, pp. 336-45.

NCAOP (2001), "Income: ageing in Ireland", Fact File No. 3, National Council for Ageing and Older People, Dublin. 
NESF (2005), "Care for older people", NESF Report No. 32, National Economic and Social Development Office, Dublin.

O'Shea, E. (2007), "Towards a strategy for older people in Ireland", Irish Medical Journal, Vol. 100 No. 8, pp. 67-9.

O'Shea, E. and Conboy, P. (2005), Planning for an Ageing Population: Strategic Considerations, National Council on Ageing and Older People, Dublin.

Pierce, M. (2008), "Constructions of ageing in Irish social policy", in Kennedy, P. and Quin, S. (Eds), Ageing and Social Policy in Ireland, University College of Dublin Press, Dublin, pp. 5-19.

Room, G. (1999), "Social exclusion, solidarity and the challenge of globalisation", International Journal of Social Welfare, Vol. 8 No. 3, pp. 166-74.

Rowles, G.D. (1983), "Place and personal identity in old age: observations from Appalachia", Journal of Environmental Psychology, Vol. 3, pp. 299-313.

Rowles, G.D. (1988), "What's rural about rural aging? An Appalachian perspective”, Journal of Rural Studies, Vol. 4, pp. 115-24.

Rowles, G.D. (1993), "Evolving images of place in ageing and 'aging in place"', Generations, Vol. 17, pp. 65-70.

Rubinstein, R.L. and Parmelee, P.A. (1992), "Attachment to place and the representation of life course by the elderly", in Altman, I. and Low, S.M. (Eds), Place Attachment, Plenum Press, New York, NY, pp. 139-63.

Rural Community Network (2004), Ageing and Rural Poverty: A Research Report, Rural Community Network, Cookstown.

Saunders, P., Naidoo, Y. and Griffiths, M. (2008), "Towards new indicators of disadvantage: deprivation and social exclusion in Australia", Australian Journal of Social Issues, Vol. 43 No. 2, pp. 175-94.

Savikko, N., Routasalo, P., Tivis, R.S., Strandberg, T.E. and Pitala, K.H. (2005), "Predictors and subjective causes of loneliness in an aged population", Archives of Gerontology and Geriatrics, Vol. 41, pp. 223-33.

Scharf, T. and Bartlam, B. (2008), "Ageing and social exclusion in rural communities", in Keating, N. (Ed.), Rural Ageing: A Good Place to Grow Old?, Policy Press, Bristol, pp. 97-108.

Scharf, T., Phillipson, C. and Smith, A.E. (2005), "Social exclusion of older people in deprived urban communities of England", European Journal of Ageing, Vol. 2, pp. 76-87.

Shucksmith, M. and Chapman, P. (1998), "Rural development and social exclusion", Sociologia Ruralis, Vol. 38, pp. 225-42.

Shumaker, S.A. and Taylor, R.B. (1983), "Toward a clarification of people-place relationships: a model of attachment to place", in Feimer, N. and Geller, E.S. (Eds), Environmental Psychology: Directions and Perspectives, Praeger Publishers, New York, NY, pp. 219-51.

Thrift, N. (1999), "Steps towards an ecology of place", in Massey, D., Allen, J. and Sarre, P. (Eds), Human Geography Today, Polity Press, Cambridge, pp. 295-322.

Walsh, K. and O'Shea, E. (2008), "Responding to rural social care needs: older people empowering themselves, others and their community", Health and Place, Vol. 14, pp. 795-805.

Walsh, K., Murray, M., Connolly, S., Allen, M., McGuire, C., Gavin, M., McDonagh, J. and HARC Research Network (2010), Older People in Rural Communities: Exploring Attachment, Contribution and Diversity in Rural Ireland and Northern Ireland, HARC Research Network, Irish Centre for Social Gerontology, Galway.

Wenger, C. (2001), "Myths and realities of ageing in rural Britain", Ageing and Society, Vol. 21, pp. 117-30.

\section{Corresponding author}

Eamon O'Shea can be contacted at: eamon.oshea@nuigalway.ie

To purchase reprints of this article please e-mail: reprints@emeraldinsight.com Or visit our web site for further details: www.emeraldinsight.com/reprints 